UDC 331

LBC 65.24

\title{
STAFF MARKETING IN MODERN RUSSIAN CONDITIONS
}

\author{
Nataliya N. Kretova \\ Voronezh State Technical University, Voronezh, Russian Federation \\ Natalya N. Mitina \\ Voronezh State Technical University, Voronezh, Russian Federation
}

\begin{abstract}
The conception of staff marketing, which was developed abroad, is effectively used in the developed countries for a long time. Its main advantage consists in the possibility of organizing some planning for the implementation of staff strategy: staff marketing provides the enterprise on the long-term basis with human resources capable of forming strategic potential, which would allow to implement the planned activities. Numerous problems of formation and development of civilized market relations in our country do not allow to fully implement the detailed models of staff marketing in domestic realities. On the basis of the analysis of theoretical developments and factors that have a practical impact on the implementation of marketing personnel in modern Russian conditions, the authors describe the essential elements of the conception. The primary purposes of staff marketing for domestic enterprises, grouped into the internal and external marketing are substantiated and disclosed. The special attention is paid to increasing the staff loyalty, which has dominant influence on business outcomes. The algorithm of events for the development of motivation system is proposed; at the stage of studying job satisfaction it is recommend to apply analytical calculations with the use of Shewhart control charts. Unlike traditional statistical tools based on the inspection of already implemented results, this approach is aimed at preventing negative tendencies and avoids losses associated with dissatisfaction with difficulty, as the individual employee and the team as a whole. Modern Russian enterprises can fully realize the conception of staff marketing only through rethinking of the consequences for all directions of work with the staff, as reflected in the definition of objectives, motivating staff and ensuring social responsibility of the enterprise.
\end{abstract}

Key words: primary goals of staff marketing, external and internal staff marketing, Shewhart control charts in the analysis of job satisfaction, staff marketing, market economy.

УДК 331

ББК 65.24

\section{ОСОБЕННОСТИ РЕАЛИЗАЦИИ МАРКЕТИНГА ПЕРСОНАЛА В СОВРЕМЕННЫХ РОССИЙСКИХ УСЛОВИЯХ}

\author{
Наталия Николаевна Кретова \\ Воронежский технический университет, г. Воронеж, Российская Федерация \\ Наталья Николаевна Митина \\ Воронежский технический университет, г. Воронеж, Российская Федерация
}

Аннотация. Концепция маркетинга персонала, получившая импульс развития за рубежом, давно и
успешно используется практиками в развитых странах. Основное ее преимущество заключается в возмож-
ности организации определенного планирования для реализации кадровой стратегии: маркетинг персонала
открывает предприятию на длительную перспективу человеческие ресурсы, способные образовать страте-
гический потенциал, посредством которого можно реализовывать запланированные мероприятия. Много-
численные трудности формирования и развития цивилизованных рыночных отношений в нашей стране не
позволяют в полной мере реализовать в отечественных реалиях развернутые модели маркетинга персонала. 
В статье на основе проведенного анализа теоретических разработок и факторов, оказывающих практическое влияние на реализацию маркетинга персонала в современных российских условиях, предлагаются важнейшие элементы данной концепции. Обоснованы и раскрыты первоочередные цели маркетинга персонала для отечественных предприятий, сгруппированные в контуры внешнего и внутреннего маркетинга. Особое значение уделяется повышению лояльности персонала, оказывающей доминирующее влияние на результаты работы предприятия. Предлагается алгоритм мероприятий по разработке системы мотивации; на этапе изучения удовлетворенности трудом рекомендуется применение аналитических расчетов с использованием контрольных карт Шухарта. В отличие от традиционных статистических инструментов, основанных на проверке уже осуществившихся результатов, такой подход нацелен на предупреждение негативных тенденций и позволяет избежать потерь, связанных с неудовлетворенностью трудом как отдельного работника, так и коллектива в целом. Для современных российских предприятий в полной мере реализовать концепцию маркетинга персонала можно только посредством переосмысления последствий для всех направлений работы с персоналом, отраженного в целеполагании, мотивировании персонала и обеспечении социальной ответственности предприятия.

Ключевые слова: первоочередные цели маркетинга персонала, внешний и внутренний маркетинг персонала, контрольные карты Шухарта в анализе удовлетворенности трудом, маркетинг персонала, рыночная экономика.

Маркетинг персонала рассматривается многими авторами как вид управленческой деятельности, направленный на долгосрочное обеспечение организации человеческими ресурсами. На взгляд авторов, маркетинг персонала - это кадровая политика социально ответственного предприятия в условиях рыночной экономики. Поясним нашу точку зрения.

В конце прошлого века за рубежом и в теории и на практике укрепила свои позиции концепция маркетинга персонала. Тому способствовали следующие первичные факторы: ментальные трансформации (переоценка ценностей) трудоспособного населения, односторонний подход к выбору профессии и места работы, демографические изменения, недостаток высококвалифицированных специалистов и руководителей, новый профиль рабочего места [2, с. 67].

Российские работодатели и сегодня еще слабо понимают свою потребность в маркетинге персонала, ошибочно полагая, что это суть манипуляции. К сожалению, у многих российских предприятий присутствует потребительское отношение к персоналу, выражающееся в несоблюдении его социальных и экономических прав. В качестве доказательств можно привести такие факты, как хронические задолженности по зарплате, ставящие работников не только на грань нищеты, но и рабства; нарушения норм этики при проверках сотрудников на проходной, при осуществлении тотального видеонаблюдения, при использовании полиграфа; неоплата сверхурочной работы при фактическом 12-часовом рабочем дне; дифференциация уровня оплаты труда и карьерных перспектив в зависимости от степени неформальной приближенности к руководителю; дискриминация отдельных категорий соискателей при приеме на работу. Такое отношение к персоналу, в свою очередь, привело к существенному отставанию нашей страны в производительности труда, к заметному оттоку за рубеж высококвалифицированных специалистов, к росту демотивации, абсентеизма и текучести персонала, к наращиванию неэффективных расходов на персонал и в целом к девальвации роли HR-менеджмента.

Несмотря на это, мы наблюдаем рост организаций, стремящихся строить долгосрочные взаимовыгодные отношения с персоналом. Основными предпосылками данного процесса, на наш взгляд, явились повышение конкуренции на рынке (каждый сотрудник может потенциально своим уходом к конкуренту снизить конкурентные преимущества данной организации), диффузия организационно-управленческих инноваций со стороны западных компаний, открывших в России свои представительства, а также принятие ряда законов, ограничивающих произвол работодателей.

Итак, обратимся более подробно к избранному направлению исследования. Вопросы маркетинга персонала были затронуты такими учеными, как Л. Берри, Р. Бюнер, Е. Дитман, К. Гренроос, Б.Р. Льюис, А. Кибанов, И. Дуракова, Д. Захаров, З. Якимов и др. 
В конце 80-х гг. зарубежные специалисты предложили подход, согласно которому маркетинг персонала в зависимости от дислокации делится на внешний и внутренний. Современная его интерпретация показана на рисунке 1.

Маркетинг персонала современного предприятия имеет двухуровневую структуру:

1. Внешний маркетинг персонала - это система деятельности, позволяющая его субъектам оценивать состояние рынка труда, тенденции его изменения и принимать обоснованные управленческие решения в сфере найма (трудоустройства), содействия занятости и эффективного использования человеческого капитала [3, с. 4].

2. Внутренний маркетинг персонала - это подход к персоналу фирмы как клиентам и обеспечение их продуктом, который удовлетворяет их потребности [9, с. 30]. Такой подход трансформирует традиционные элементы маркетинга «4Р» (продукт, цена, продажи и продвижение продукта) в следующие элементы маркетинга персонала: диапазон задач и ответственности работника, степень мотивации сотрудника или усилия, которые сотрудник готов приложить для выполнения своих должностных обязанностей, организационная структура фирмы, аспекты организационной культуры.

Эффективные модели маркетинга персонала, предлагаемые зарубежными исследова- телями и практиками, предусматривают выделение внутреннего и внешнего маркетинга персонала внутри функциональных блоков: исследования и планирования; выбора рынков персонала; работы средств массовой информации; формирование договорных отношений; организации рабочих мест; содействия развитию; заботы о персонале. Каждый из этих блоков имеет свою сложную структуру (см., например: [10, с. 65]).

Такие развернутые модели маркетинга персонала, успешно реализуемые и доказывающие свою эффективность в европейских странах, что подтверждается опубликованными данными по таким компаниям, как Ауди, Мерседес, Мессершмидт, Хенкель и др. [1, с. 36], пока не могут, к сожалению, в полной мере реализоваться в отечественных реалиях. Основная причина тому - продолжающаяся фаза становления цивилизованных рыночных отношений в условиях продолжающихся внешних шоков и внутренних структурных проблем [5, с. 411]. Проблемы развития человеческого капитала в нашей стране, что называется, «у всех на устах». Так, на прошедшем в январе 2017 г. Гайдаровском форуме первые лица государства подчеркивали необходимость увеличения доли высокооплачиваемых рабочих мест с высоким уровнем производительности, предотвращения процесса замещения более квалифицированных российских работников миг-



Рис. 1. Структура маркетинга персонала

Примечание. Составлено авторами. 
Н.Н. Кретова, Н.Н. Митина. Особенности реализации маркетинга персонала в современных условиях

рантами; декларировали важность формирования привлекательности российских рабочих мест; особо выделяли актуальность развития социальных сервисов, потребность в повышении стоимости оплаты труда (см., например: [6, с. 1]).

Хотя в отечественной практике есть немного примеров функционирования отдельных элементов современной модели маркетинга персонала, но говорить о серьезных успехах в реализации полной системы пока не приходится.

Тем не менее необходимо двигаться в этом направлении. Основываясь на научных разработках и опыте предприятий, попытаемся определить, что же необходимо в первую очередь современному российскому предприятию для построения эффективного маркетинга персонала.

Основные цели маркетинга персонала отечественных предприятий можно агрегировать в четыре блока (рис. 2).

Рассмотрим данные цели подробнее. Первые две относятся к контуру внешнего маркетинга персонала (КI), четвертая - к контуру внутреннего (КII), а третья - смешанная (KI-KII).

KI: Работа по достижению целей внешнего маркетинга основывается на трансляции потенциальным кандидатам на вакансию позитивной настроенности на организацию и обеспечении ее необходимыми, профессионально пригодными сотрудниками. В этом ракурсе следует решать задачи, связанные с формированием благоприятного имиджа, peпутации, HR-бренда работодателя.
Известная консалтинговая компания PWC провела в прошлом году ежегодный опрос среди генеральных директоров крупнейших российских компаний (было опрошено 107 СЕО). При оценке рыночных рисков на втором месте после риска волатильности валютного курса самым актуальным бизнесриском $47 \%$ опрошенных посчитали дефицит квалифицированных кадров [8, с. 6]. Примерно такая же картина наблюдалась и в предыдущие исследуемые периоды. В условиях устойчивого тренда нехватки высокопрофессиональных кадров на рынке труда имидж, репутация и HR-бренд являются эффективным инструментом борьбы за лучшие кадры.

KI-KII: Формирование ценностных предложений внешнему и внутреннему рынкам труда или EVP (Employee Value Proposition) это предложение, с которым предприятие хочет ассоциироваться, суть бренда, отличительные выгоды, которые может предложить сотрудникам именно эта компания, чем она действительно отличается и лучше других на рынке. EVP могут быть сгруппированы в пять групп: финансовые (оплата труда, формы материального стимулирования и др.); организационные (процедуры найма, система адаптации, системы профессионального продвижения, обучение); технические (условия труда, оснащение рабочего места); социально-психологические (стиль руководства, организационная культура, моральные поощрения) и имиджевые.

KII: Повышение лояльности персонала, как мы говорили выше, относится к целям

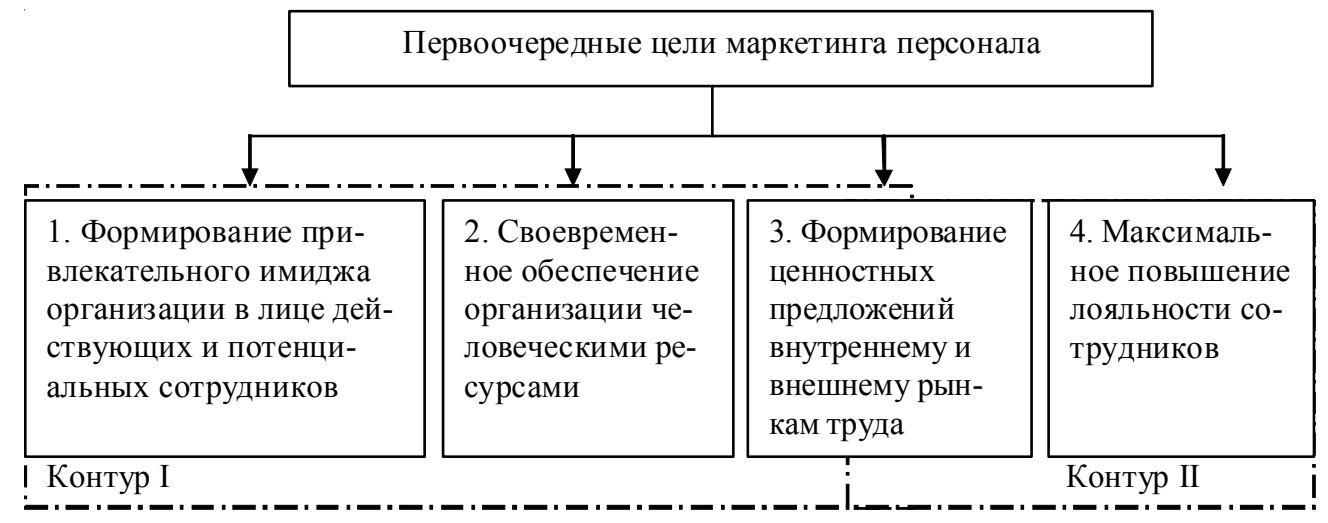

Рис. 2. Первоочередные цели маркетинга персонала отечественных предприятий Примечание. Составлено авторами. 
внутреннего маркетинга персонала. Эта сложная работа основывается на исследовании ожиданий работников по отношению к самой организации, ее руководству, условиям работы, вознаграждению, перспективам карьерного роста и обучения и направлена на взаимоотношения организации и персонала: необходимо применять маркетинговые подходы для того, чтобы побуждать персонал оставаться в организации и производительно работать.

Правильно сформированные ценностные предложения обязательно положительно скажутся на лояльности персонала. Лояльность, другими словами, верность или преданность это совпадение ценностей человека и организационных ценностей, которое обеспечивает вовлеченность его в организационные процессы, формирует причастность к работе/профессии и принадлежность к организации [7, с. 46].

Разные виды лояльности имеют разное влияние на работу в организации (табл. 1).

Целенаправленная работа по повышению лояльности сотрудников может открыть для российских предприятий новые резервы развития и роста, при этом контролируя свои расходы на персонал. Внутренний найм имеет ряд преимуществ как в экономическом, так и в социальном аспектах.

Согласно правилу Фауста, затраты на наем, включающие расходы на поиск, отбор и введе- ние нового работника в организацию, составляют 50-100 \% его будущей годовой заработной платы. Опыт предприятий свидетельствует, что фактически в зависимости от функций и уровня руководства предприятия эти затраты составляют от 25 до 500 тыс. евро. Опубликованы результаты опроса, показывающие, что 95 \% менеджеров по персоналу отмечают усиливающуюся значимость подготовки управленческих кадров из своего персонала [1, с. 35].

Высокий уровень лояльности сотрудников часто является следствием правильно разработанной системы мотивации. А для этого как минимум нужно осуществить следующие этапы:

1) изучить потребности персонала;

2) распределить сотрудников по группам в зависимости от доминирующей направленности их потребностей;

3) оценить потребности сотрудников;

4) сформировать и внедрить систему мотивации персонала с учетом внутреннего позиционирования компании, рекламы ее деятельность и продуктов среди работников;

5) оценить эффективность внедренных мероприятий. робнее.

Рассмотрим некоторые из этапов под-

Изучать потребности сотрудников желательно с момента приема на работу. На собесе-

\section{Влияние лояльности на результаты работы предприятия}

Таблица 1

\begin{tabular}{|l|l|}
\hline \multicolumn{1}{|c|}{ Виды лояльности персонала } & \multicolumn{1}{|c|}{ Показатели } \\
\hline $\begin{array}{l}\text { 1. Лояльность, основанная на эмоциях и } \\
\text { личных симпатиях (вовлеченность): нра- } \\
\text { вится сама работа, компания, руководство, } \\
\text { коллектив }\end{array}$ & $\begin{array}{l}\text { - Уовышение производительности } \\
\text { - Повышение отношений } \\
\text { - Идентификация и принятие организаци- } \\
\text { онных целей и ценностей, желание при- } \\
\text { надлежать к организации, готовность доб- } \\
\text { ровольно прилагать усилия на благо орга- } \\
\text { низации }\end{array}$ \\
\hline $\begin{array}{l}\text { 2. Лояльность, основанная на принятых } \\
\text { обязательствах (активная лояльность): } \\
\text { персональная ответственность за достиже- } \\
\text { ние определенных целей и выполнение } \\
\text { функций }\end{array}$ & - Повышение производительности \\
\hline $\begin{array}{l}\text { 3. Лояльность, основанная на привычке и } \\
\text { инертности (пассивная лояльность, удов- } \\
\text { летворенность): неплохие условия, ожида- } \\
\text { ние выслуги, невозможность выгоднее } \\
\text { реализоваться на рынке труда }\end{array}$ \\
\hline
\end{tabular}

Примечание. Составлено авторами. 
Н.Н. Кретова, Н.Н. Митина. Особенности реализации маркетинга персонала в современных условиях

довании кандидаты могут заполнить специальную анкету, оценив важность каждого вопроса по определенной шкале. Разработать анкету может отдел кадров. Однако если нужно подобрать сотрудников для отдела продаж или других служб, работающих с клиентами, для конкретизации вопросов и дополнений можно обратиться, например, к специалистам по маркетингу.

Анкета должна включать блоки вопросов:

- о приемлемых условиях труда (зарплата, рабочее место, дополнительные привилегии, стабильность);

- самореализации (карьерный рост, лидерство);

- межличностных отношениях внутри компании.

Необходимо регулярно проводить анкетирование и работающего персонала. Потребуется более глубокая анкета. В ней сотрудники оценивают не только важность перечисленных потребностей, но и то, насколько компания их удовлетворяет. Например, в анкетах можно оставлять поля для личных пожеланий каждого сотрудника. Информация будет более достоверной только если используются анонимные анкеты.

Как и при работе с внешними клиентами, нужно обязательно изучать жалобы персонала: это незаменимая информация для оптимизации бизнес-процессов. Чтобы понять, чем недовольны сотрудники, достаточно завести книгу жалоб. Главное, чтобы она была доступна каждому сотруднику. Изучение потребностей сотрудников проходит в два этапа.

На первом этапе надо определить общие настроения: что наиболее и что наименее востребовано в коллективе.

На втором этапе изучаются потребности отдельных сотрудников. Необходимо опросить каждого (уже не анонимно). В ходе беседы нужно постараться выяснить и остальные приоритеты работника. Эта информация даст директору по персоналу пищу для размышлений. Вопервых, насколько откровенны сотрудники (совпадают ли общие настроения в анонимных анкетах с ответами в ходе беседы). Во-вторых, можно оценить потребности каждого человека и понять, подходят ли эти люди его компании. В-третьих, можно будет понять, как удовлетворить сотрудников и побудить их к эффективной работе с клиентами [4, с. 167].
В ходе исследования можно предложить сотрудникам оценить определенные показатели по 10-балльной шкале. В рамках исследования были проведены несколько опросов с периодичностью 6 месяцев на одном из машиностроительных предприятий Воронежа. При этом опрашивались 20 сотрудников среднего звена управленческих отделов. Аналитические расчеты проводились с использованием контрольных карт Шухарта.

Алгоритм расчета с использованием контрольных карт Шухарта предполагает определение средней величины. Средняя величина это обобщающий показатель статистической совокупности, который погашает индивидуальные различия значений статистических величин, позволяя сравнивать разные совокупности между собой. Простая средняя величина рассчитывается по следующей общей формуле (1):

$$
\bar{X}=\sqrt[m]{\frac{\sum X^{m}}{N}},
$$

где $X$ - значения отдельных статистических величин или середин группировочных интервалов; $m$ - показатель степени, от значения которого зависят следующие виды степенных средних величин; $N$ - количество носителей показателя.

Размах вариации рассчитывается как разность между максимальным и минимальным значениями признака по формуле (2):

$$
R=X_{\max }-X_{\min }
$$

где $X_{\max }$ - максимальное значение признака; $X_{\min }-$ минимальное значение признака.

В рамках анализа рассчитывался нижний контрольный предел для оценки уровня обозначенных показателей по формуле (3):

$$
\mathrm{LCL} 1=X_{\mathrm{cp}}-A_{2} \times R
$$

Аналогично получаем верхний контрольный предел по формуле (4):

$$
\mathrm{LCL} 1=X_{\mathrm{cp}}+A_{2} \times R
$$

где $X_{\text {ср }}$ - среднее значение средних значений по подгруппе; $R$ - средний размах; $A_{2}-$ инженерный коэффициент, зависящий от размера подгруппы. 
Отметим, что все формулы и табличные коэффициенты можно найти, например, в ГОСТ 50779.42-99. При помощи таблицы 2 из ГОСТа находим значение инженерного коэффициента: $A_{2}=0,18$.

Результирующие данные по одному из анализируемых сотрудников приведены в таблице 2.

Анализ отклонений по показателям качества организации труда позволит руководителю не только быть в курсе настроений своих сотрудников, но и вовремя выявлять отклонения, которые могут являться сигналами как положительных, так и отрицательных тенденций. Что касается нашего примеpa, то все показатели сотрудника $N$ находятся в пределах нормы для данного предприятия. Это, с одной стороны, хорошо, но с другой, с учетом низкого уровня некоторых из них, можно сказать, что существуют определенные проблемы, характерные для предприятия в целом.

Руководству рассматриваемого предприятия необходимо разработать и внедрить мероприятия по совершенствованию системы мотивации персонала с учетом целевых ори- ентиров и позиционирования компании по упомянутым выше направлениям EVP.

Завершающим этапом как формирования маркетинга персонала в целом, так и мероприятий по совершенствованию системы мотивации персонала предприятия в частности должна быть оценка эффективности внедренных мероприятий.

Систему оценки следует формировать для конкретного предприятия, в зависимости от особенностей ведения бизнеса. Но в качестве основы можно использовать такие коэффициенты: текучесть кадров, стабильность кадров, выбытие кадров, стаж работы в организации, обеспеченность кадрами, обеспеченность специалистами, использование специалистов по назначению, квалификация работников. Алгоритмы их исчисления представлены в литературе [2, с. 166].

Исходя из вышесказанного, можно сделать следующие выводы:

- организации, формирующие и реализующие маркетинг персонала, имеют ряд преимуществ: повышение производительности труда, снижение текучести, эффективную мотивацию сотрудников и высокую их лояльность;

Выявление отклонений в процессе реализации маркетинга персонала на примере анализа показателей удовлетворенности трудом с использованием карт Шухарта

\begin{tabular}{|l|c|c|c|c|c|c|}
\hline \multicolumn{1}{|c|}{ Показатели } & $\begin{array}{c}\text { Оценка по- } \\
\text { казателя } \\
\text { конкретным } \\
\text { сотрудником }\end{array}$ & $\begin{array}{c}\text { Среднее } \\
\text { значение } \\
\text { показателя } \\
\text { по данной } \\
\text { группе со- } \\
\text { трудников }\end{array}$ & $\begin{array}{c}\text { Размах } \\
\text { вариа- } \\
\text { ции }\end{array}$ & $\begin{array}{c}\text { Верхняя } \\
\text { граница } \\
\text { карты } \\
\text { средних }\end{array}$ & $\begin{array}{c}\text { Нижняя } \\
\text { граница } \\
\text { карты } \\
\text { средних }\end{array}$ & Примечания \\
\hline $\begin{array}{l}\text { Профессиональный } \\
\text { рост }\end{array}$ & 6 & 5,4 & 3 & 4,86 & 5,94 & $\begin{array}{c}\text { В пределах } \\
\text { нормы }\end{array}$ \\
\hline Стабильная работа & 7 & 6,1 & 3 & 5,56 & 6,64 & То же \\
\hline Достойная зарплата & 6 & 5,7 & 5 & 4,8 & 6,6 & » \\
\hline $\begin{array}{l}\text { Приемлемые рабо- } \\
\text { чие условия }\end{array}$ & 6 & 5,9 & 4 & 5,18 & 6,62 & " \\
\hline $\begin{array}{l}\text { Повышение уровня } \\
\text { знаний }\end{array}$ & 6 & 4,8 & 5 & 3,9 & 5,7 & " \\
\hline Интересная работа & 5 & 5,1 & 5 & 4,2 & 6 & " \\
\hline Самореализация & 4 & 4,3 & 4 & 3,58 & 5,02 & " \\
\hline $\begin{array}{l}\text { Хорошие отношения } \\
\text { в коллективе }\end{array}$ & 5 & 4 & 4 & 3,28 & 4,72 & " \\
\hline $\begin{array}{l}\text { Причастность к } \\
\text { развитию компании }\end{array}$ & 4 & 4,2 & 4 & 3,48 & 4,92 & " \\
\hline $\begin{array}{l}\text { Справедливая } \\
\text { оценка работы }\end{array}$ & 4 & 4 & 3 & 3,46 & 4,54 & " \\
\hline
\end{tabular}

Примечание. Составлено авторами. 
- грамотно организованный маркетинг персонала в целом повышает конкурентоспособность предприятия и его продукции, формирует стратегическую конкурентоспособность предприятия;

- в маркетинге персонала заинтересована только социально ориентированная компания с хорошим уровнем организационной культуры, ставящая задачи долгосрочной работы на рынке.

Для современных российских предприятий воспринимать самих себя с позиций маркетинга персонала можно только переосмыслив последствия для всех направлений работы с персоналом, организации труда. При ориентации на маркетинг персонала должно трансформироваться самосознание руководителей и функциональных специалистов управления: через переход от роли формального лидера, опирающегося лишь на иерархическую вертикаль власти, к роли инициатора, координатора, помощника, функционально фокусирующегося на целеполагании, мотивировании персонала и обеспечении социальной ответственности предприятия.

\section{СПИСОК ЛИТЕРАТУРЫ}

1. Дуракова, И. Б. Развитие имиджевых технологий в управлении персоналом. Опыт Германии / И. Б. Дуракова // Управление. - 2013. - № 1. C. $35-38$.

2. Кибанов, А. Я. Управление персоналом организации: стратегия, маркетинг, интернационализация / А. Я. Кибанов, И. Б. Дуракова. - М. : ИНФРА-М, 2009. - $301 \mathrm{c.}$

3. Киян, Л. П. Маркетингрынка труда / Л. П. Киян. - Воронеж : Изд-во Воронеж. ун-та, 1995. 93, [1] c.

4. Кретова, Н. Н. Контроллинг маркетинга как эффективный инструмент повышения производительности труда / Н. Н. Кретова // Развитие предприятий машиностроения в России: проблемы, опыт, перспективы : сб. материалов Междунар. науч.-практ. конф. Ч. 2. - Воронеж : Изд-во Воронеж. гос. техн. ун-та, 2015. - С. 165-170.

5. Кретова, Н. Н. Стратегия развития персонала как ответ на современные вызовы / Н. Н. Кретова, Н. Н. Митина // Современные проблемы права, экономики и управления. - 2016. - № 2 (3). C. $411-417$.

6. Мануйлова, А. Эксперты Гайдаровского форума обсудили инвестиции в человеческий ка- питал / А. Мануйлова // Коммерсант. - 2017 [сайт]. - Электрон. текстовые дан. - Режим доступа: http://www.kommersant.ru/doc/3188925. - Загл. с экрана.

7. Митина, Н. Н. Ценностная компонента организационной культуры на примере IT-компании / Н. Н. Митина // Современная экономика: проблемы и решения. -2016 . - Т. 80, № 8. - С. 46-53.

8. Российский выпуск 19-го ежегодного опроса руководителей крупнейших компаний мира // PWC. - 2016. - Электрон. текстовые дан. - Режим доступа: http://www.pwc.ru/ru/ceo-survey/assets/ ceo-survey-2016/19th-ceo-survey-rus-eversion.pdf. Загл. с экрана.

9. Grundlagen des Marketing / P. Kotler, G. Armstrong, J. Sauders, V. Wong. - 2007. - P. 30.

10. Personalmanagement, Band 1. Personalbeschaffung. DIHT - Bildungs-GmbH, 1999. S. 65 .

\section{REFERENCES}

1. Durakova I.B. Razvitie imidzhevykh tekhnologiy v upravlenii personalom. Opyt Germanii [The Development of Image Technologies in Staff Management. German Experience]. Upravlenie, 2013, no. 1, pp. 35-38.

2. Kibanov A.Ya., Durakova I.B. Upravlenie personalom organizatsii: strategiya, marketing, internatsionalizatsiya [Staff Management: Strategy, Marketing, Internationalization]. Moscow, INFRA-M Publ., 2009. 301 p.

3. Kiyan L.P. Marketing rynka truda [Labour Marketing]. Voronezh, Izd-vo Voronezh. un-ta, 1995. 93 p.

4. Kretova N.N. Kontrolling marketinga kak effektivnyy instrument povysheniya proizvoditelnosti truda [Controlling Marketing as an Effective Tool for Enhancing Productivity]. Razvitie predpriyatiy mashinostroeniya $v$ Rossii: problemy, opyt, perspektivy: sb. materialov Mezhdunar. nauch.-prakt. konf. Ch. 2. [Development of Engineering Enterprises in Russia: Problems, Experience and Prospects. Proceedings of the International Scientifica and Practical Conference. Part 2]. Voronezh, Izd-vo Voronezh. gos. tekhn. un-ta, 2015, pp. 165-170.

5. Kretova N.N., Mitina N.N. Strategiya razvitiya personala kak otvet na sovremennye vyzovy [The Strategy of Staff Development as a Response to Current Challenges]. Sovremennye problemy prava, ekonomiki i upravleniya, 2016, no. 2(3), pp. 411-417.

6. Manuylova A. Eksperty Gaydarovskogo foruma obsudili investitsii $\mathrm{v}$ chelovecheskiy kapital [Gaidar Forum Experts Discussed the Investment in Human Capital]. Kommersant, 2017. URL: http:// www.kommersant.ru/doc/3188925. 


\section{УПРАВЛЕНИЕ ЭКОНОМИЧЕСКИМ РАЗВИТИЕМ}

7. Mitina N.N. Tsennostnaya komponenta organizatsionnoy kultury na primere IT-kompanii [Axiological Components of Organizational Culture on the Example of IT-Companies]. Sovremennaya ekonomika: problemy i resheniya, 2016, vol. 80, no. 8, pp. 46-53.

8. Rossiyskiy vypusk 19-go ezhegodnogo oprosa rukovoditeley krupneyshikh kompaniy mira
[The Russian Edition of the $19^{\text {th }}$ Annual Survey of Managers of Major Companies in the World]. $P W C$, 2016. URL: http://www.pwc.ru/ru/ceo-survey/assets/ ceo-survey-2016/19th-ceo-survey-rus-eversion.pdf.

9. Kotler P., Armstrong G., Sauders J., Wong V. Grundlagen des Marketing, 2007, p. 30.

10. Personalmanagemcnt, Band 1. Personal beschaffung. DIHT - Bildungs-GmbH, 1999, p. 65.

\section{Information About the Authors}

Nataliya N. Kretova, Candidate of Sciences (Economics), Associate Professor, Department of Economics and Management at Engineering Company, Voronezh State Technical University, Prosp. Moskovsky, 14, 394026 Voronezh, Russian Federation, nnkretova@yandex.ru.

Natalya N. Mitina, Candidate of Sciences (Economics), Associate Professor, Department of Staff Management, Voronezh State University, Universitetskaya Sq., 1, 394018 Voronezh, Russian Federation, mitina_nn@mail.ru.

\section{Информация об авторах}

Наталия Николаевна Кретова, кандидат экономических наук, доцент кафедры экономики и управления на предприятии машиностроения, Воронежский технический университет, просп. Московский, 14, 394026 г. Воронеж, Российская Федерация, nnkretova@yandex.ru.

Наталья Николаевна Митина, кандидат экономических наук, доцент кафедры управления персоналом, Воронежский государственный университет, Университетская площадь, 1, 394018 г. Воронеж, Российская Федерация, mitina_nn@mail.ru. 